Acta vet. scand. 1973, 1/, 758-760.

Brief Communication

\title{
THE DIAGNOSTIC VALUE OF $\gamma$-GT-ESTIMATIONS ON BLOOD SAMPLES COLLECTED IN CONJUNCTION WITH EXSANGUINATION OF CATTLE
}

It has been shown that the validity of certain clinical-biochemical blood values may change immediately post-mortem (McCaughey 1967, Jönsson \& Pehrson 1968). The aim of this investigation was to establish whether $\gamma$-GT-estimations on blood samples collected at slaughter are of diagnostic value.

\section{Material and methods}

The material consisted of blood samples taken on a normal slaughter day in the autumn 1972 (Oct. 5) from 51 slaughter cows. From each animal two blood samples were collected. One was taken some hours before slaughter, the other in conjunction with exsanguination following stunning by captive-bolt pistol. The second blood sample was taken in such a way that the blood was sampled not too soon after cutting of the blood vessel and not so late that the blood flow had started to reduce. All samples were coded so as to be unidentifiable by those who performed the analyses.

The following analytical methods were used: భ-GT-glutamyltranspeptidase * (Szasz 1969);

Aspartate aminotransferase * formerly called SGOT (Morgenstern et al. 1966, mod. for autoanalyzer);

Inorganic phosphate (Shinowara et al. 1942, slightly mod.).

\section{Results}

The results of all analyses of the samples are shown in Table 1. In the table the differences between samples taken with a cannula before slaughter and those taken by exsanguination are shown. For inorg. $P$ the average difference between the samples before and after the killing was $0.30 \mathrm{mg}$ per $100 \mathrm{ml}$. This difference is significant. For the SGOT-values no significant difference

* (EC 2.3.2.1).

* (EC 2.6.1.1). 
Table 1. Survey of results.

\begin{tabular}{|c|c|c|c|c|c|c|c|}
\hline & $\mathbf{n}$ & Before & s & After & $\mathbf{s}$ & Diff. & $\overline{\mathbf{s}}$ \\
\hline Inorg. $P \mathrm{mg} / 100 \mathrm{ml}$ & 48 & 5.04 & 0.93 & 5.34 & 0.95 & $0.30 * *$ & 0.10 \\
\hline SGOT i.u. & 48 & 41.40 & 7.88 & 42.35 & 8.32 & 0.95 & 1.27 \\
\hline$\gamma$-GT i.u. & 48 & 26.13 & 8.81 & 21.94 & 7.68 & $4.19^{* *}$ & 0.68 \\
\hline
\end{tabular}

was found between samples taken before and after the slaughter. For $\gamma$-GT there was a negative difference between the average values in samples taken before and after the killing. This difference too is significant.

\section{Discussion}

Jönsson \& Pehrson found that analyses of blood samples collected in conjunction with exsanguination generally appear to be subject to greater errors than can be explained by the errors in the analytical methods. In the present investigation values for inorg. $P$ were found to be higher in post-mortem samples than in samples taken ante-mortem. The same direction of change has been found for inorg. P-estimations ante- and post-mortem by McCaughey as well as by Jönsson \& Pehrson.

For the SGOT-estimations the results found here indicate no significant differences between samples taken before and after the killing. This is in disagreement with Jönsson \& Pehrson. They compared the differences in SGOT-estimations before and after slaughter in 21 cows notified for emergency slaughtering. They found a significant but not numerically great difference between the samples taken before and after the slaughter, and they therefore conclude that the samples taken in conjunction with exsanguination would still be of good diagnostic significance.

For $\gamma$-GT no previous information is available concerning the diagnostic value of samples taken in conjunction with exsanguination. In experimental bovine fascioliasis (Simesen et al. 1973) $\gamma$ GT-activities have been reported to increase up to 20 times the preinfection levels. The differences found in this investigation (an average decrease of about $20 \%$ ) are numerically not so great that $\gamma$-GT-estimations post-mortem would not still be of good diagnostic significance. 
Mogens G. Simesen and Palle Storm

The Institute for Internal Medicine, Royal Veterinary and Agricultural University, Copenhagen, Denmark.

\section{REFERENCES}

Jönsson, G. \& B. Pehrson: The diagnostic value of blood samples taken in conjunction with exsanguination of cows. Acta vet. scand. $1968,9,378-380$.

McCaughey, W. J.: Comparison of ante- and post-mortem electrolyte values. Vet. Rec. 1967, 80, 33.

Morgenstern, S., M. Oklander, J. Auerbach, J. Kaufman \& B. Klein: Automated determination of serum glutamic oxaloacetic transaminase. Clin. Chem. 1966, 12, 95-111.

Shinowara, G. Y., L. M. Jones \& H. L. Reinhart: The estimation of serum-inorganic phosphatase and "acid" and "alkaline" phosphatase activity. J. biol. Chem. 1942, 142, 921—933.

Simesen, M. G., K. Nielsen \& P. Nansen: Serum enzymes in bovine fascioliasis. Studies on serum $\gamma$-glutamyl transpeptidase $(\gamma$-GT) and serum glutamic oxaloacetic acid transaminase (SGOT) activities during the course of an experimental infection. Res. vet. Sci. $1973,15,32-36$.

Szasz, G.: A kinetic photometric mcthod for serum $\gamma$-glutamyl transpeptidase. Clin. Chem. 1969, 15, 124.

(Received October 15, 1973).

Reprints may be requested from: M. G. Simesen, The Institute for Internal Medicine, Royal Veterinary and Agricultural University, Bülowsvej 13, DK-1870 Copenhagen V, Denmark. 